\title{
Grand Challenges and Opportunities in Photovoltaic Materials and Devices
}

\author{
Shujuan Huang * \\ Sustainable Energy Research Centre, School of Engineering, Macquarie University, Sydney, NSW, Australia
}

Keywords: renewable energy, photovoltaics, terawatt production, c-Si solar cells, perovskite solar cells, tandem solar cells

The past few years have seen severe weather extremes causing horrendous disasters, including bush fires, droughts, and floods. It is never as urgent as today to commit to climate goal by reducing greenhouse emission. More and more countries have agreed to reach net-zero emission by 2050-2060. To achieve this goal, $69 \%$ of total electricity needs to be generated from renewables by 2050 , with $56 \%$ from wind and solar energy (BloombergNEF, 2020). Therefore, photovoltaic (PV) technology which converts solar energy, the largest renewable energy resource, to electricity will play a key role in this revolutionary energy transition.

Fortunately, PV technology has been rapidly maturing in the last decade, compounded with a variety of technologies including the wafer-based first-generation PV, thin film PV, and advanced concept PV. Wafer-based crystalline silicon (c-Si) PV technology is dominating the PV market, sharing its $95 \%$. This is attributed to the continuing module price reduction, with a $23.5 \%$ learning rate (1976-2019). The historical spot price of c-Si solar module was only $\$ 0.23$ USD/Wp in 2019 (VDMA, 2020). The advancement in cell and module performance in the last few decades is undoubtedly the driving force for such historical PV cost reduction. Improving cell and module efficiency will continue to play a significant role in lowering the levelized cost of electricity (LCOE) by saving the cost of land and balance of systems while producing the same amount of electricity.

For laboratory research cells, three world record efficiencies have been reported: $25 \%$ for p-type

\section{OPEN ACCESS}

Edited and reviewed by: Marco Peccianti,

University of Sussex, United Kingdom

${ }^{*}$ Correspondence:

Shujuan Huang

shujuan.huang@mq.edu.au

Specialty section:

This article was submitted to

Photovoltaic Materials and Devices, a section of the journal

Frontiers in Photonics

Received: 10 January 2021

Accepted: 08 February 2021

Published: 12 April 2021

Citation:

Huang S (2021) Grand Challenges and Opportunities in Photovoltaic Materials and Devices.

Front. Photonics 2:651766. doi: $10.3389 /$ fphot.2021.651766 passivated emitter and rear contact cell (PERC cell) (Green et al., 2017), 26.1\% for p-type rear IBC cell, and $26.7 \%$ for n-type rear IBC cell (Green et al., 2020). These efficiencies are approaching the theoretical efficiency limit of Si cells at $29.3 \%$. Even though the current record cell technologies are not completely compatible with the industry technology, these high efficiencies are of importance as they provide the industries with $\mathrm{R} \& \mathrm{D}$ research guide for further improving mass-production industrial cell performance. Further closing the gap between the record efficiencies and theoretical efficiency limit will be challenging. The short circuit current of the record n-type rear IBC cell has already reached 97.5\% of its theoretical limit. Future research effort will need to be made to reduce carrier recombination so as to improve open circuit voltage and fill factor (Ehrler et al., 2020).

PERC cell is the dominant industrial PV technology, and its share in the market will continue to grow within the next decade. Commercial PV modules based on PERC cells have achieved 20\% efficiency. Further reducing the gap between the module efficiency and research cell efficiency will be the future focus of R\&D research, while maintaining the low manufacturing cost.

Although the manufacturing costs of c-Si solar cells and modules have been dramatically reduced in the past decade, continuing cost reduction will be urgently required for further supporting the terawatt large-scale integration of renewables into the electricity generation. So far, PV cost reduction has been largely attributed to the reduction of materials consumption, increased manufacture throughput, and reduced manufacturing tool cost. Moving forward to terawatt production, more innovations will be needed to improve cost-effectiveness of fabrication processes with less energy input, shortened processing time, and low-cost materials.

Thin-film solar cells are considered as the second-generation PV technology that has low-cost potential due to reduced amount of materials compared to the first-generation wafer-based PV cells. 
However, their market share has dropped significantly from 15\% in 2010 to $5 \%$ in 2019. CdTe and CIGS are the predominant thin film technology in the current market. Moving to the terawatt production era, the rarity of tellurium and indium will be an issue for such a large-scale application.

Recently, metal halide perovskite solar cells have emerged as a promising thin-film PV technology owing to their inherently excellent optical and electronic properties such as large optical absorption coefficient, high carrier mobility, long carrier lifetime, and low mid-gap state density (Kim et al., 2019). The past few years have seen extraordinarily rapid progress in their power conversion efficiency, increasing from $3.8 \%$ in 2009 to $25.5 \%$ in 2020, comparable to the record efficiencies of c-Si (NREL, 2020). Detailed techno-economic analysis has also demonstrated that perovskite PV technology is potentially very cost-effective (Cheng et al., 2018) because of its low-temperature solution processibility and small material consumption. The globally intensive and collective research has significantly improved perovskite materials' quality and stability, and device durability increasing prospects for commercialization. This is mainly due to the advancement in 1) deposition processes producing better crystalline and compact perovskite films, 2) understanding of photo- and electronic-physics underlying device operation, and 3) passivation of defects associated with the perovskite materials and device structures.

So far, huge research effort from perovskite research community has been committed to the improvement in small cell $\left(<1 \mathrm{~cm}^{2}\right)$ efficiency and stability, leading to the world record efficiency at $25.5 \%$. However, the cell efficiency drops significantly to $21.6 \%$ when just enlarging the cell area to $1 \mathrm{~cm}^{2}$, while the best module efficiency is just $17.47 \%$, with an area of $804 \mathrm{~cm}^{2}$ (Green et al., 2020). This large gap is undoubtedly hindering the commercialization of perovskite PV technology. Perovskite cells have a more complex device structure than c-Si devices; therefore, there are more attributes responsible for the poor performance when scaling up the devices. One of these is the large amount of the defects. The ease of perovskite device fabrication at low processing temperature makes this solution processable technology very promising for low-cost manufacturing. On the other hand, defects can be readily generated within the grains, at the grain boundaries and on the surface of the film, due to their low formation energy. Despite the great research effort in developing passivation strategies leading to improved efficiency and stability for small cells (Kim et al., 2019), the defect formation in the large-scale perovskite film is not uniform and hard to be passivated. This is particularly detrimental for perovskite module performance. Moreover, the solution processes for the fabrication of perovskite cells are not as controllable as c-Si PV. Batch-bybatch variations in film and defect formation add another hurdle for module development. Therefore, future research efforts are required in further identifying and understanding the defect mechanisms as well as developing more controllable processes to mitigate the ununiformed film and defect formation.

Other emerging thin-film solar cells have also made impressive progress in terms of conversion efficiency. In the past 3 years, organic photovoltaics (OPV) has demonstrated ground-breaking progress by the use of non-fullerene acceptors, achieving a record efficiency of $15.2 \%$ for a $1-\mathrm{cm}^{2}$ device and $18.2 \%$ for a small device (Green et al., 2020). The new accepters have remarkably improved the non-radiative recombination losses, increasing open-circuit voltage. However, the carrier collection rate is still relatively low compared to that of perovskite and $\mathrm{c}-\mathrm{Si} \mathrm{PV}$ cells, leaving much room to improve.

Similarly, quantum dot solar cells have also demonstrated rapid progress in the last decade, with a record small-cell efficiency at $16.6 \%$ for perovskite quantum dot (Hao et al., 2020) and $13.8 \%$ for PbS quantum dot cells (Sun et al., 2020). These quantum dot PV cells have great potential for the applications in new deployment of PV technology.

The tandem PV technology is the most developed advanced PV concept. 47.1 and $38.8 \%$ efficiency have been demonstrated, respectively, for 6-junction (under 143 suns) and 5-junction (under 1 sun) III-V tandems (Green et al., 2020). Higher efficiency provided by tandem PV cells will play a more and more important role in improving cost-effectiveness of PV technology. For the PV market and industry to take-up the technology, it is particularly important to develop low-cost c-Si-based tandem PV. The International Technology Roadmap for Photovoltaic (ITRPV) has highlighted the potential of emerging c-Si-based tandem PV technology by predicting the mass production in 2023 and its market share at $1 \%$ in 2024 and 5\% in 2029 (VDMA, 2019; VDMA, 2020).

Apart from III-V on c-Si, the performance of two-junction perovskite-Si tandem cells has rapidly increased from $14 \%$ (uncertified) in 2015 (Mailoa et al., 2015) to 29.15\% (certified) in 2020 (Al-Ashouri et al., 2020). Several companies are commercializing this rapid developing technology including Oxford PV that has demonstrated $28 \%$ efficient and stable perovskite-Si tandems in 2018. Certainly, in terms of the device efficiency, there is still large room to improve toward the theoretical limit of $\sim 40 \%$. In addition to the same challenges faced by perovskite cells, processing compatibility of each sub-cell is a challenge for further improving device performance. More effective interfacial carrier recombination layers are also required. Despite the rapid development of two-junction perovskite-Si tandems in the past 5 years, research in multi-junction perovskite-Si cells has obviously lagged behind. With the recent demonstration of perovskite-perovskite tandems and larger bandgap semitransparent perovskite cells, multi-junction perovskite-Si technology should be able to follow the trajectory of its two-junction counterparts.

Moving forward to $100 \%$ renewable energy era in the next 30 years, PV has to reach terawatt/year production scale, increasing its electricity market share from the current $5 \%$ to over 23\% (BloombergNEF, 2020). This will be an extremely challenging task faced by the PV research and industry community. More diversified new deployment applications will be needed for increasing solar energy uptake. One example is building integrated photovoltaics (BIPV). The energy consumption in buildings is $\sim 40 \%$ of the total energy consumption, significantly contributing to the greenhouse gas emission. On the other hand, these buildings can become zero 
emission by integrating PV to their roofs, facades, and windows. Fortunately, various types of PV technology have been developed in parallel to the main stream c-Si PV. Thin-film technologies have the advantages of being light weight and flexible. They can find applications in niche markets of structure-integrated PV. Perovskite, OPV, and quantum dot PV have great potential in these new deployments due to their broad range bandgap tunability, providing high esthetic standards, low-cost printing,

\section{REFERENCES}

Al-Ashouri, A., Köhnen, E., Li, B., Magomedov, A., Helmpel, H., Caprioglio, P., et al. (2020). Monolithic perovskite/silicon tandem solar cell with $>29 \%$ efficiency by enhanced hole extraction. Science 370, 1300-1309. doi:10.1126/ science.abd4016

BloombergNEF (2020). Energy outlook 2020. Available at https://about.bnef.com/ new-energy-outlook/

Cheng, N, Ho-Baillie, A., Vak, D., Gao, M., Green, M., and Egan, R. (2018). Manufacturing cost and market potential analysis of demonstrated roll-to-roll perovskite photovoltaic cell processes. Sol. Energy Mater. Sol. Cells 174, 314-324. doi:10.1016/j.solmat.2017.08.038

Ehrler, B., Alarcón-Lladó, E., Tabernig, S. W., Veeken, T., Garnett, E. C., and Polman, A., (2020). Photovoltaics reaching for the Shockley-Queisser limit. ACS Energy Lett. 5, 3029-3033. doi:10.1021/acsenergylett.0c01790

Green, M. A., Hishikawa, Y., Warta, W., Dunlop, E. D., Levi, D. H., Hohl-Ebinger, J., et al. (2017). Solar cell efficiency tables (version 50). Prog. Photovolt. Res. Appl. 25, 668-676. doi:10.1002/pip.2909

Green, M., Dunlop, E., Hohl-Ebinger, J., Yoshita, M., Kopidakis, N., and Hao, X. (2020). Solar cell efficiency tables (version 57). Prog. Photovolt. Res. Appl. 29, 3-15. doi:10.1002/pip.3371

Hao, M., Bai, Y., Zeiske, S., Ren, L., Liu, J., Yuan, Y., et al. (2020). Ligand-assisted cation-exchange engineering for high-efficiency colloidal $\mathrm{Cs}_{1-\mathrm{x}} \mathrm{FA}_{\mathrm{x}} \mathrm{PbI}_{3}$ quantum dot solar cells with reduced phase segregation. Nat. Energy 5, 79-88. doi:10.1038/s41560-019-0535-7 or coating processes enabling large area cells/modules and high efficiency improving cost-effectiveness.

\section{AUTHOR CONTRIBUTIONS}

The author confirms being the sole contributor of this work and has approved it for publication.

Kim, J., Ho-Baillie, A., and Huang, S. (2019). Review of novel passivation techniques for efficient and stable perovskite solar cells. Sol. RRL 3, 1800302-1800310. doi:10.1002/solr.201800302

Mailoa, J. P., Bailie, C. D., Johlin, E. C., Hoke, E. T., Akey, A. J., Nguyen, W. H., et al. (2015). A 2-terminal perovskite/silicon multijunction solar cell enabled by a silicon tunnel junction. Appl. Phys. Lett. 106, 121105-121109. doi:10.1063/1.4914179

NREL (2020). Best research-cell efficiency chart. Available at: https://www.nrel. gov/pv/cell-efficiency.html (Accessed January 15, 2021).

Sun, B., Johnston, A., Xu, C., Wei, M., Huang, Z., Jiang, Z., et al. (2020). Monolayer perovskite bridges enable strong quantum dot coupling for efficient solar cells. Joule 4, 1-15. doi:10.1016/j.joule.2020.05.011

VDMA (2019). International technology roadmap for photovoltaic (ITRPV). 10th Edn. Available at https://itrpv.vdma.org/en/

VDMA (2020). International technology roadmap for photovoltaic (ITRPV). 11th Edn. Available at https://itrpv.vdma.org/en/

Conflict of Interest: The author declares that the research was conducted in the absence of any commercial or financial relationships that could be construed as a potential conflict of interest.

Copyright (c) 2021 Huang. This is an open-access article distributed under the terms of the Creative Commons Attribution License (CC BY). The use, distribution or reproduction in other forums is permitted, provided the original author(s) and the copyright owner(s) are credited and that the original publication in this journal is cited, in accordance with accepted academic practice. No use, distribution or reproduction is permitted which does not comply with these terms. 